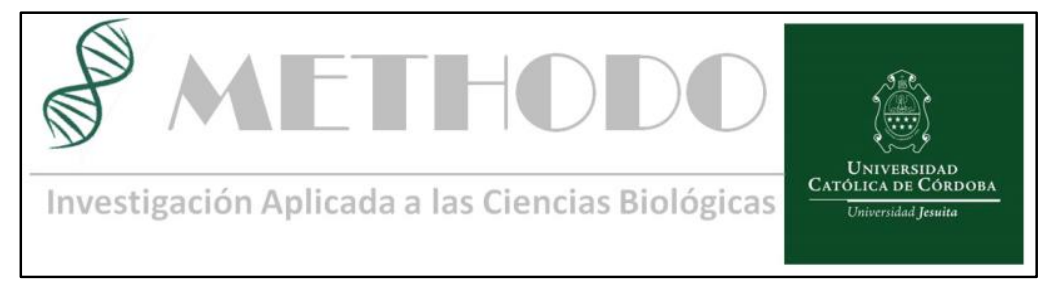

EDITORIAL Methodo 2017;2(3):77-78 DOI: $10.22529 / \mathrm{me} .2017 .2(3) 01$

Recibido 01 Ago 2017| Aceptado 15 Sep 2017 | Publicado 30 Sep 2017

\title{
Educación Médica Continua y formación de postgrado
}

\section{Continuing Medical Education and Postgraduate Training}

Hace unos cuantos años atrás, en una de nuestras reuniones de cátedra, nuestro querido Profesor Humberto José Redondo, comentó la experiencia vivida en ocasión de en un encuentro de estudiantes de la Carrera de Medicina, en una Facultad latinoamericana. En ese momento, el Decano de esa casa de altos estudios, saludo a todos los que participaban del evento, llamándolos: Colegas y les dijo así porque todos, profesores y alumnos, eran estudiantes de Medicina, lo que los igualaba en una misma condición. Traigo a colación este recuerdo, ya que nos permite un marco para reflexionar acerca de dos grandes temas, uno el de la educación continua, un imperativo en nuestros tiempos y el rol de la formación de posgrado en este desafío.

Hemos sido testigos del desarrollo vertiginoso de las ciencias en los finales del siglo $\mathrm{XX}$ e inicios del $\mathrm{XXI}$, habiéndose conducido a una sensible diversificación y subespecialización de todas las ciencias, en especial de las ciencias médicas y biológicas. Hoy como nunca antes, el término obsolescencia del conocimiento (1), se ha mostrado en toda su dimensión. En este sentido, la educación de posgrado a través de un conjunto de procesos de enseñanza-aprendizaje deben garantizar la preparación de los graduados universitarios para complementar, actualizar y profundizar los conocimientos y habilidades necesarios, vinculados directamente al ejercicio profesional, los avances científico-técnicos y las necesidades de las entidades en que desarrollan su función, mediante la creación de ofertas educativas formales de posgrado de calidad que aseguren estos objetivos.

La educación de posgrado, surge como una extensión de las carreras de grado y como una necesidad de perfeccionamiento o especialización de la práctica profesional, pero debe también responder a las necesidades sociales, económicas y culturales de la población. Las características individuales del proceso enseñanza-aprendizaje en la educación de posgrado, se manifiestan en los objetivos del proceso de "aprender a aprender" y "enseñar a pensar" (2), a un estudiante adulto con capacidad crítica y reflexiva, mediante la aplicación de técnicas pedagógicas de problematización alrededor de las situaciones concretas.

Revista Methodo: Investigación Aplicada a las Ciencias Biológicas. Facultad de Medicina. Universidad Católica de Córdoba. Jacinto Ríos 571 Bo Gral. Paz. X5004FXS. Córdoba. Argentina. Tel.: (54) 351 4517299/ E-mail: methodo@ucc.edu.ar / Web: methodo.ucc.edu.ar | EDITORIAL Methodo 2017;2(3):7778 
Las instituciones académicas relacionadas con la formación y desarrollo de los recursos humanos en salud, tienen una responsabilidad primordial, que es la de desarrollar un profesional con sólida formación científico tecnológica y un desafío, que es el de articular con los procesos de investigación, sus procesos de enseñanza aprendizaje, promoviendo el desarrollo del capital humano de la población a la que asisten.

De esta manera, la educación permanente constituye un requerimiento fundamental para el fortalecimiento y mantenimiento de la competencia profesional y en última instancia para elevar la calidad de la actividad profesional, siendo la educación de posgrado, la alternativa que ofrece las instancias académicas formales, que aseguran, mediante procesos formativos sistemáticos, la generación de un recurso humano capacitado para dar respuesta a las necesidades de la comunidad y los sistemas de salud y en nuestro caso, con la calidad y calidez humana necesarias para la integralidad de esa respuesta.

Ampliar los sistemas educativos, mediante ofertas académicas de posgrado de calidad y excelencia, son propias de una sociedad moderna.

La calidad de estas ofertas educativas de posgrado, en respuesta a las necesidades de la educación continua, estarán condicionadas fundamentalmente por su pertinencia e impacto social y su relevancia científico-técnica.

Esperamos que ante la necesidad formativa de nuestros graduados y de la búsqueda de respuestas por parte de la comunidad y, mediante el trabajo incansable de nuestros docentes y el acompañamiento incondicional de las autoridades, podamos estar a la altura de este apasionante desafío de brindar una formación académica de excelencia en nuestros programas de educación de posgrado.

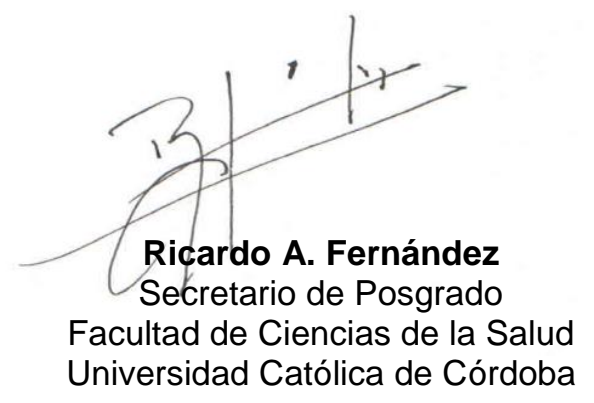

(1) ASLIB, the Association for Information Management. "The concept of obsolescence in relation to knowledge. Managing Information. 2007; 14 (1): 50-53

(2) Santaella CM. Aprender a pensar-aprender a aprender. Habilidades de pensamiento y aprendizaje autorregulado. Bordón 60 (2), 2008, 123-137 